Check for updates

Cite this: RSC Adv., 2017, 7, 42614

Received 2nd June 2017

Accepted 24th August 2017

DOI: $10.1039 / \mathrm{c} 7 \mathrm{ra06159e}$

rsc.li/rsc-advances

\section{Preparation, characterization, bioactivity and degradation behavior in vitro of copper-doped calcium polyphosphate as a candidate material for bone tissue engineering}

\begin{abstract}
Chengrui Guo, ${ }^{a} \mathrm{Li} \mathrm{Li}^{\text {b }}$ Shuangshuang Li, ${ }^{\mathrm{a}}$ Yaping Wang ${ }^{\mathrm{a}}$ and Xixun Yu (DD *a
In this study, copper, as one of the essential trace elements in the human body, was introduced into calcium polyphosphate (CPP) to prepare a novel scaffold in bone tissue engineering: copper-doped calcium polyphosphate (CCPP) scaffolds. This novel scaffold was characterized by XRD, FTIR and SEM. The porosity and mechanical properties of CCPP scaffolds were also investigated. Finally, its bioactivity and degradation behavior in vitro were exploited. The results suggested that low-content copper doping had no significant influence on the structure of CPP. The compressive strength of CCPP with 70\% porosity was 5-9 $\mathrm{MPa}$ which met the strength requirements of cancellous bone (2-12 $\mathrm{MPa})$. The results of degradation experiments from the weight loss of scaffolds and the release of ions obtained from ICPOES showed that both the incorporation of copper and acidic metabolites from osteoblasts could promote the degradation of CCPP scaffolds. The amount of $\mathrm{Cu}^{2+}, \mathrm{Ca}^{2+}$ and $\mathrm{PO}_{4}{ }^{3-}$ released from various scaffolds in osteoblast-mediated degradation might be used to elucidate the cytocompatibility of CCPP scaffolds with HUVECs/osteoblasts. MTT assay showed that $0.05 \%$ CCPP scaffolds showed a good cytocompatibility with HUVECs/osteoblasts. The ELISA assay showed that $0.05 \%$ CCPP scaffolds could promote the secretion of VEGF, ALP and OCN from osteoblasts as well as VEGF from HUVECs, which indicated its good ability to stimulate osteogenesis and angiogenesis. According to the chemical composition and structure of $0.05 \%$ CCPP scaffolds, we inferred that $0.05 \%$ CCPP scaffolds showed better cytocompatibility and ability to stimulate osteogenesis and angiogenesis due to the synergy effects of copper and the energy produced by the breakage of PlOIP bonds between $\left[\mathrm{PO}_{3}{ }^{-}\right]$units in CCPP compared with CPP scaffolds and other Cu-containing biomaterials such as copper-doped hydroxyapatite. The results obtained in our study suggest that $0.05 \%$ CCPP scaffold is a promising biomaterial for bone repairing applications.
\end{abstract}

\section{Introduction}

More and more orthopedic problems are becoming more devastating and costly with an aging population and prolonged life expectancy. Thus, there is a great need for a great quantity of bone replacement materials with excellent properties. However, at present there are no heterologous or synthetic bone substitutes available that have superior or even the same biological or mechanical properties compared to bone. Therefore, there is a necessity to develop novel treatments or improve the performance of synthetic bone substitutes. Over the years, some synthetic bone scaffolds have been investigated to repair damaged bone tissue and to overcome the lack of donor tissue.

${ }^{a}$ College of Polymer Science and Engineering, Sichuan University, Chengdu, Sichuan Province 610065, P. R. China. E-mail: yuxixun@163.com

${ }^{b}$ Department of Oncology, The 452 Hospital of Chinese PLA, Chengdu, Sichuan Province 610021, P. R. China
The ideal scaffolds for bone repair should possess not only biocompatibility, osteoconductivity and osteoinductivity, but also the degradation characteristics and the ability to stimulate angiogenesis. ${ }^{1-3}$ Angiogenesis plays an important role in bone formation and has great effects on bone defect repair. ${ }^{4}$ Bioactive scaffolds, such as bioceramics, are ideal bone substitute materials, but the clinical success of these synthetic grafts could not be achieved. ${ }^{5}$ So, research is ongoing to improve the mechanical properties and biocompatibility of scaffolds, to promote osteoblast adhesion, growth and differentiation, and to allow vascular ingrowth and bone-tissue formation.

As a kind of bioactive scaffolds, bioceramics and bioactive glasses are known to have osteoconductive properties and thus are potential bone substitute materials. Phosphate-based ceramics are a range of ceramics made up of components which all occur naturally in the body. More interestingly, their dissolution rates can be tailored to suit with their end application simply by varying the compositions of the ceramics. ${ }^{6,7}$ As 
a kind of phosphate-based ceramics, biodegradable calcium polyphosphate (CPP) has been designed as grafts for bone repairing, growth or substitution because of its mechanical strength, stable physicochemical properties, excellent biocompatibility and controllable degradability. ${ }^{8}$ In a way, the energy produced by the breakage of $\mathrm{P} \backslash \mathrm{O} \backslash \mathrm{P}$ bonds between $\left[\mathrm{PO}_{3}{ }^{-}\right]$units in CPP, which was similar to the breaking of high-energy anhydride linkages in the adenosine triphosphate, could be used for cell-growth. This could be the reason why the cytocompatibility of CPP were prior to HA and TCP. ${ }^{9}$ Although CPP scaffolds possess generally controllable degradability and outstanding biocompatibility, their angiogenesis seem to be not prominent. Therefore, various approaches have been developed to enhance angiogenesis-ability of synthetic scaffolds such as HA, CPP and bioactive glasses. Among these approaches, the doping of bioceramic scaffolds with small quantities of bioinorganic ions is gaining increasing interest as an alternative way to the delivery of angiogenic growth factors for stimulating angiogenesis and osteogenesis. ${ }^{10-12}$ Compared to growth factors, the bioinorganic angiogenic factors such as metal ions released from scaffolds can have some great superiorities, such as high stability and lower costs. Specifically, it was reported that copper $\left(\mathrm{Cu}^{2+}\right)$ ions could promote angiogenesis through stabilising the expression of hypoxia-inducible factor (HIF-1 $\alpha$ ), thus mimicking hypoxia, which is very important in the differentiation and recruitment of cells and in formation of neovascularization..$^{11,13}$ Moreover, copper exerts a critical role in degradation of extracellular matrix (ECM) and ECM remodeling by regulating gene expression, protein levels and activities of MMPs. ${ }^{14}$ Copper has also been reported to have an osteogenic influence in promoting the differentiation of osteoblastic cells and MSCs. ${ }^{15,16}$ However, the concentrations of copper ion exceeding optimal level can lead to cytotoxicity due to the production of free radical species, and bring about the risk of neurodegenerative diseases. ${ }^{17,18}$ Hence, in order to determine the optimal dose of copper introduced into scaffolds, the research on the degradation of Cu-doped scaffold and how it correlates with the texture of the materials are very important, which are also key considerations for their applications in tissue engineering.

In recent years, several biomaterials containing $\mathrm{Cu}$ have been developed and investigated to study the benefits of copper ions on stimulating angiogenesis. Nevertheless, the direct incorporation of $\mathrm{Cu}$ ions into CPP scaffolds has not been investigated to date. Thus, this study was undertaken to create CPP scaffolds with varying amounts of $\mathrm{Cu}$ and assess the effects of $\mathrm{Cu}$ in CPP on the performance of scaffolds and activity of cells (osteoblasts and endothelial cells). Moreover, as mentioned above, in order to understand the degradation property of CCPP which plays an important role in the successful and long-term implantation of bone-repairing biomaterials, the degradation behaviors of CCPP in vitro (include the solution-mediated and osteoblast-mediated) were also investigated. By analyzing the results obtained from this research, we can provide the theoretical basis for the clinical application of CCPP. By doping copper ions into CPP, we provide a way to improve the properties of bioceramics and offer a novel idea on the application of bone repair materials. Also, we believe that it may give inspiration to others worked on the bone repair materials, draw their attention to CPP and CCPP scaffolds and extend the applications and development of bone tissue engineering.

\section{Materials and methods}

\subsection{Preparation of porous CPP and CCPP scaffolds}

Chemical precipitation method was used in our research to prepare the CCPP powders. CPP scaffolds and CCPP scaffolds with various amount of $\mathrm{Cu}$ were prepared in the following way: $\mathrm{CaCO}_{3}$ and $\mathrm{CuCO}_{3}$ were dissolved in $2 \mathrm{M}$ phosphoric acid solution, and then stirred several minutes until the starting powders were completely dissolved. The solution was kept at room temperature overnight and then calcium dihydrogen phosphate $\left(\mathrm{Ca}\left(\mathrm{H}_{2} \mathrm{PO}_{4}\right)_{2}\right)$ and calcium dihydrogen phosphate $\left(\mathrm{Cu}\left(\mathrm{H}_{2} \mathrm{PO}_{4}\right)_{2}\right)$ were formed, the chemical reaction equations are as follows:

$$
\begin{aligned}
& \mathrm{CaCO}_{3}+2 \mathrm{H}_{3} \mathrm{PO}_{4}=\mathrm{Ca}\left(\mathrm{H}_{2} \mathrm{PO}_{4}\right)_{2}+\mathrm{H}_{2} \mathrm{O}+\mathrm{CO}_{2} \\
& \mathrm{CuCO}_{3}+2 \mathrm{H}_{3} \mathrm{PO}_{4}=\mathrm{Cu}\left(\mathrm{H}_{2} \mathrm{PO}_{4}\right)_{2}+\mathrm{H}_{2} \mathrm{O}+\mathrm{CO}_{2}
\end{aligned}
$$

Subsequently, the solution was transferred to rotary evaporation apparatus and was evaporated in vacuum. Then, the resulting white precipitates were filtered, the distilled water was used to wash the precipitates until the $\mathrm{pH}$ of filtrate was 7 . The precipitates were dried for 10 hours by infrared heat lamp to form the powders. In order to prepare CCPP, these powders were first calcined at $500{ }^{\circ} \mathrm{C}$ for $10 \mathrm{~h}$, and then were melted by heating to $1200{ }^{\circ} \mathrm{C}$. The melt was quickly quenched on frozen water to obtain the bluish transparent frits. The amorphous frits were ground and screened to yield powders $(<75 \mu \mathrm{m})$, then the powders were pressed at $98 \mathrm{MPa}$ after mixing with the stearic acid and $3 \mathrm{wt} \%$ poly(vinyl alcohol) additive, finally sintered for $1 \mathrm{~h}$ at $800{ }^{\circ} \mathrm{C}$ to obtain porous CCPP cylinder $(10 \mathrm{~mm}$ diameter and $2 \mathrm{~mm}$ thickness). Porous CPP scaffolds were prepared similar to CCPP scaffold and served as controls.

The mass of $\mathrm{CaCO}_{3}$ and $\mathrm{CuCO}_{3}$ with various $\mathrm{Cu} / \mathrm{Ca}$ molar ratios using in this study are listed in Table 1.

Table 1 The mass of $\mathrm{CaCO}_{3}$ and $\mathrm{CuCO}_{3}$ with different molar ratio of $\mathrm{Cu}: \mathrm{Ca}$

\begin{tabular}{lll}
\hline & \multicolumn{2}{l}{ Materials } \\
\cline { 2 - 3 } $\mathrm{Cu}: \mathrm{Ca}$ & $\mathrm{CuCO}_{3}(\mathrm{~g})$ & $\mathrm{CaCO}_{3}(\mathrm{~g})$ \\
\hline 0 & 0 & 20 \\
0.01 & 0.0023 & 19.998 \\
0.05 & 0.0115 & 19.988 \\
0.1 & 0.0234 & 19.977 \\
0.2 & 0.0468 & 19.953 \\
0.5 & 0.1147 & 19.885
\end{tabular}




\subsection{Characterization of porous CPP and CCPP scaffolds}

The scaffolds was analyzed by the X'Pert Pro MPD X-ray diffractometer (XRD, Netherlands, Philips) to assess their crystal structure. The scaffolds were also tested by Fourier Transform Infrared Spectrometer (FTIR, America, Wicolet Inc.) to investigate the presence of specific chemical group in the scaffolds. The morphologies of various CCPP and CPP scaffolds were observed by scanning electron microscopy (SEM, Japan Electronics Co., Ltd.). Compression strengths of samples with $10 \mathrm{~mm}$ diameter and $10 \mathrm{~mm}$ thickness were tested by Ag-10TA Universal material testing machine. The test were carried out at room temperature in air and a cross-head speed of $0.5 \mathrm{~mm} \min ^{-1}$ was selected. Besides, liquid displacement method was used to measure the porosity of porous scaffolds.

\subsection{Degradation experiments}

2.3.1 Preparation of the degradation solution. In this study, solution-mediated degradation and osteoblast-mediated degradation were carried out to evaluate the degradation behaviors of CCPP. The preparation of SBF was according to protocol reported by Kokubo et al. ${ }^{19}$ with ion concentrations which were listed in Table 2 almost equal to those of human blood plasma. The PH of SBF solution was adjusted close to 7.4 by adding tris(hydroxymethyl)aminomethane and $1 \mathrm{M}$ hydrochloricacid (HCL) at $37{ }^{\circ} \mathrm{C}$. MG63 human osteoblasts (purchased from West China Hospital, Sichuan University, China) were cultured in DMEM medium supplemented with $10 \%(\mathrm{v} / \mathrm{v})$ bovine calf serum (BCS, Hyclone) and antibiotics at $37{ }^{\circ} \mathrm{C}$ in humidified $95 \%$ air/5\% $\mathrm{CO}_{2}$. Cells from passage 3 were used for investigating osteoblast-mediated degradation of CCPP scaffolds.

2.3.2 Characterization of samples during the degradation. CPP, 0.01\% CCPP, 0.05\% CCPP, 0.1\% CCPP, 0.2\% CCPP, 0.5\% CCPP scaffolds were totally soaked in $4 \mathrm{ml}$ of SBF solution in clean bottles respectively ( $n=3$, in each group). Then seal the bottles and put them into a water-bathing constant temperature vibrator with $37{ }^{\circ} \mathrm{C}$. The medium was changed every 3 days. The samples were taken out at predetermined time intervals of $3,6,12,18,21$, 27 and 30 days. Also, cells with a density of $1.5 \times 10^{5} \mathrm{ml}^{-1}$ were seeded on the samples in the 24-well plate, meanwhile, scaffolds soaking in $1 \mathrm{ml}$ fresh culture medium without cells in 24-well plate were served as blank control samples. The mediums were changed every other day during cell-culture period.

An obsolete release-medium was gathered for determining the concentration of $\mathrm{Ca}^{2+}, \mathrm{Cu}^{2+}$ and $\mathrm{PO}_{4}{ }^{3-}$. The collected supernatants were diluted by distilled water and the concentrations of $\mathrm{Ca}^{2+}$ and $\mathrm{Cu}^{2+}$ were tested by ICP-MS (IRIS, Thermo
Elemental, USA). The concentration of $\mathrm{PO}_{4}{ }^{3-}$ was measured by molybdenum blue photometric method. ${ }^{20}$ The cumulative release amount of $\mathrm{Ca}^{2+}, \mathrm{Cu}^{2+}$ and $\mathrm{PO}_{4}{ }^{3-}$ were calculated at the designated times according to the results of measurements mentioned above. Scanning Electron Microscopy (SEM, JSM$5900 \mathrm{LV}$, JEOL, Japan) was used to analyze the surface morphological changes of the samples. In osteoblast-mediated degradation, concentrated nitric acid $\left(\mathrm{HNO}_{3}\right)$ and hydrogen peroxide $\left(\mathrm{H}_{2} \mathrm{O}_{2}\right)\left(V_{\text {(sample) }}: V_{\left(\mathrm{H}_{2} \mathrm{O}_{2}\right)}: V_{\left(\mathrm{HNO}_{3}\right)}=1: 2: 2\right)$ were added to the collected solution to remove the organic compounds before testing by ICP-MS. The scaffolds needed to be soaked in pancreatin, washed with PBS and dried at $50{ }^{\circ} \mathrm{C}$ to remove cells covered on the scaffolds before testing by SEM. Also, the weights of scaffolds, before and after degrading, needed to be recorded to calculate the weight loss in solution-mediated degradation and osteoblast-mediated degradation. At predetermined time, the samples were rinsed in distilled water and dried in vacuum at $50{ }^{\circ} \mathrm{C}$ before weighting. The percentage of weight loss was calculated by the following equation:

$$
\text { Weightloss }(\%)=\left(W_{0}-W_{t}\right) / W_{0} \times 100 \%
$$

where $W_{0}$ is the initial weight of the sample and $W_{t}$ is the weight of the dried sample at time $t$.

\subsection{The cytocompatibility of CCPP scaffolds with MG63 (human osteoblasts) and HUVEC (human umbilical vein endothelial cells)}

MTT assay was carried out to evaluate the effect of CCPP scaffolds on proliferation of MG63 and HUVEC. In brief, sterilized CPP and various CCPP scaffolds were soaked in a culture medium for $24 \mathrm{~h}$ at $37^{\circ} \mathrm{C}$ and then MG63 were cultured on each scaffold in the 96-well plate for 2, 4, 6, 14 and 21 days, while HUVEC were cultured on each sample in an another 96-well plate for 2, 4 and 6 days. At the predetermined time, the plate was added with $20 \mu \mathrm{l}$ per well of MTT solution $\left(5 \mathrm{mg} \mathrm{ml}^{-1}\right.$ in PBS) and then incubated at $37{ }^{\circ} \mathrm{C}$ for $4 \mathrm{~h}$ to form formazan crystals. After that, the medium was sucked off and $200 \mu \mathrm{l}$ of dimethyl sulfoxide was added into each well to dissolve the formazan crystals. The optical density at $492 \mathrm{~nm}$ was measured by a microplate reader (Model 550, Bio Rad Corp. USA).

Furthermore, the growth and distribution of MG63 and HUVEC on CPP and CCPP scaffolds after 4 days were investigated by fluorescence microscope. Cells with a density of $6 \times$ $10^{4} \mathrm{ml}^{-1}$ were seeded on the scaffolds in the 24 -well plate. After 4 days, the medium was all siphoned off and the scaffolds were washed by PBS solution $\left(0.01 \mathrm{~mol} \mathrm{l}^{-1}, \mathrm{pH}=7.4\right)$. Then, $400 \mu \mathrm{l}$ of fluorescein diacetate (FDA) solution $\left(10 \mu \mathrm{g} \mathrm{ml}{ }^{-1}\right)$ was added to the 24-well plate. After incubated at $37^{\circ} \mathrm{C}$ for 5 minutes, the

Table 2 Ion concentrations ( $\mathrm{mM}$ ) of SBF and human blood plasma

\begin{tabular}{|c|c|c|c|c|c|c|c|c|}
\hline & $\mathrm{Na}^{+}$ & $\mathrm{K}^{+}$ & $\mathrm{Ca}^{2+}$ & $\mathrm{Mg}^{2+}$ & $\mathrm{Cl}^{-}$ & $\mathrm{HCO}_{3}{ }^{-}$ & $\mathrm{HPO}_{4}{ }^{3-}$ & $\mathrm{SO}_{4}{ }^{2-}$ \\
\hline SBF & 142.0 & 5.0 & 2.5 & 1.5 & 148.8 & 4.2 & 1.0 & 0.5 \\
\hline Human plasma & 142.0 & 5.0 & 2.5 & 1.5 & 103.0 & 27.0 & 1.0 & 0.5 \\
\hline
\end{tabular}


surfaces of scaffolds were observed under fluorescence microscope. Besides, the growth of cells on the scaffolds was observed at the $21^{\text {st }}$ day by SEM to investigate cell attachment on the scaffolds. The cell/scaffold constructs were pretreated by rinsing with PBS three times and fixed with glutaraldehyde (2.5\% in PBS, v/v) for $2 \mathrm{~h}$. Then the constructs were dehydrated in a graded ethanol concentrations $(30 \%, 50 \%, 70 \%, 80 \%, 90 \%$, $95 \%$ and $100 \%)$. The critical point drying of the cell/scaffold constructs was performed with liquid $\mathrm{CO}_{2}$. Then the constructs were coated with gold and observed by SEM (Japan Electronics Co., Ltd). Human osteoblastic sarcoma cells (MG63, human osteoblasts) and human umbilical vein endothelial cells (HUVEC, endothelial cells) used in our experiments were both purchased from West China Hospital, Sichuan University, China. The cells were cultured in growth medium [high Dulbecco's Modified Eagle's Medium (DMEM, Gibcobrl), supplemented with $10 \%$ bovine calf serum (BCS, Hyclone), $100 \mathrm{U} \mathrm{ml}^{-1}$ penicillin (Sigma) and $100 \mathrm{U} \mathrm{ml}^{-1}$ streptomycin (Solarbio) solution] and incubated at $37{ }^{\circ} \mathrm{C}$ in a humidified atmosphere (5\% $\mathrm{CO}_{2}$ in $95 \%$ air). Until confluence, cells were passaged at a $1: 2$ split ratio following trypsinization with $0.25 \%$ trypsin (Gibcobrl). Cells from passage 3 were used for the related experiments.

\subsection{The effects of CPP and CCPP scaffolds on osteogenic and angiogenic growth factors secretion from osteoblasts/ endothelial cells}

The effects of CPP and CCPP scaffolds on osteogenic and angiogenic growth factors secretion from osteoblasts/ endothelial cells were determined using a double ligand enzyme-linked immunosorbent assay (ELISA). MG63 and HUVEC cells were cultured and seeded on CPP and CCPP scaffolds with the same way mentioned above. After incubated at $37{ }^{\circ} \mathrm{C}$ for 6 days, supernatant liquid was collected for ELISA assay through centrifugation and the effects of CPP scaffolds with varying amounts of $\mathrm{Cu}$ on vascular endothelial growth factor (VEGF) secretion from HUVEC and secretion of alkaline phosphatase (ALP), VEGF and osteocalcin (OCN) from MG63 were evaluated by ELISA. ELISA assay was run according to the manufacturer's instructions (R\&D Corp.). A standard curve was plotted to determine the VEGF, ALP, and OCN concentration.

\subsection{Statistical analysis}

Statistical analysis was performed with SPSS 13.0. Experimental data was presented as means \pm standard deviation (SD). Results were analyzed by one-way ANOVA with a student's $t$-test. A $p$ value of $<0.05$ was considered to be statistically significant.

\section{Results and discussion}

\subsection{Characterization of CPP and CCPP scaffolds}

Fig. 1 shows the XRD pattern of CCPP after sintering at different temperature. It indicated from Fig. 1(A) that the CCPP-samples presented amorphous phase after sintering at $550{ }^{\circ} \mathrm{C}$. Meanwhile, we also found that the amorphous frits could not form the scaffolds when sintering at high temperature more than
$820{ }^{\circ} \mathrm{C}$. Therefore, the CCPP-samples sintering at temperature less than $550{ }^{\circ} \mathrm{C}$ or more than $820^{\circ} \mathrm{C}$ could not be used as bone tissue repairing scaffolds. Fig. 1(B)-(D) show the XRD profiles of CCPP sintering at $560{ }^{\circ} \mathrm{C}, 600{ }^{\circ} \mathrm{C}$ and $800{ }^{\circ} \mathrm{C}$ respectively. As shown in figure, the characteristic peaks in the XRD profiles of various CCPP were in line with the XRD profile of $\beta$-CPP $\left[\mathrm{Ca}\left(\mathrm{PO}_{3}\right)_{2}\right.$, JCPDS \#77-1953], especially three high characteristic peaks in each CCPP profile all presented at 3.51, 3.71 and 4.55. It suggested that there was no crystal system alteration in the incorporation of low-dose of copper into $\beta$-CPP. It indicated that $\mathrm{Cu}^{2+}$ might have been perfectly doped into the structural frame of the $\beta$-CPP crystal. According to the XRD profile of CCPP shown in Fig. 1(D), the CCPP-samples presented more perfect crystallization after sintering at $800{ }^{\circ} \mathrm{C}$, so we preferred to prepare $\beta$-CCPP at $800{ }^{\circ} \mathrm{C}$ in subsequent experiments.

Fig. 2 shows the FTIR spectra of CPP, $0.05 \%$ CCPP and $0.5 \%$ CCPP scaffolds. All the samples in Fig. 2 demonstrated similar characteristic peaks. $1280 \mathrm{~cm}^{-1}$ and $770 \mathrm{~cm}^{-1}$ means " $\mathrm{O}-\mathrm{P}=\mathrm{O}$ " and "O-P-O", respectively. It indicated that there were no effect on the FTIR spectra of scaffolds after incorporating into lowcontent copper ions.

Fig. 3 shows the SEM images of CPP and CCPP scaffolds. As shown in figure, doping low-content copper ions into CPP had little effect on microstructure of scaffolds. The three dimensional interconnected porosity which satisfied requirement of cells growth and nutrient/metabolic waste transportation were well-preserved. Meanwhile, compared to CPP, the crystal grains of CCPP became tiny and intimately connected with each other. Therefore, CCPP possessed a more compact bulk, which might lead to better mechanical properties.

The porosities of CCPP scaffolds measured by liquid displacement method were shown in Table 3 which were similar to the results of the literature. ${ }^{21}$ The compressive strength of CCPP scaffold with the porosity of 70\% was 5-9 MPa which met the strength requirements of cancellous bone (2-12 MPa). It indicated that this CCPP scaffold could serve as a promising candidate for bone repairing. In this paper, it would be used as test-sample in subsequent experiments. Meanwhile, the compressive strength of CCPP scaffold without pore-forming agent was closed to the compressive strength of human femur (170 MPa vs. $197 \mathrm{MPa}$ ). Based on it, the CCPP scaffold without pore-forming agent might be applied as a potential compact bone material.

\subsection{Degradation of CCPP scaffolds}

In general, it is difficult to administer test condition and provide a good repeatability in investigation on the degradation behaviors of biomaterial-grafts in vivo. However, the research on the degradation behavior of biomaterials in vitro is beneficial to know the degradation behavior of these biomaterials in vivo. The degradation rate in vitro could be helpful to predict the degradation rate in vivo, and unsuitable degradation rate might directly affect the bone healing. So the degradation behavior of biomaterial-grafts in vitro can establish a concrete foundation for investigating their degradability, and thus can provide guidance for the development of biomaterials with good 

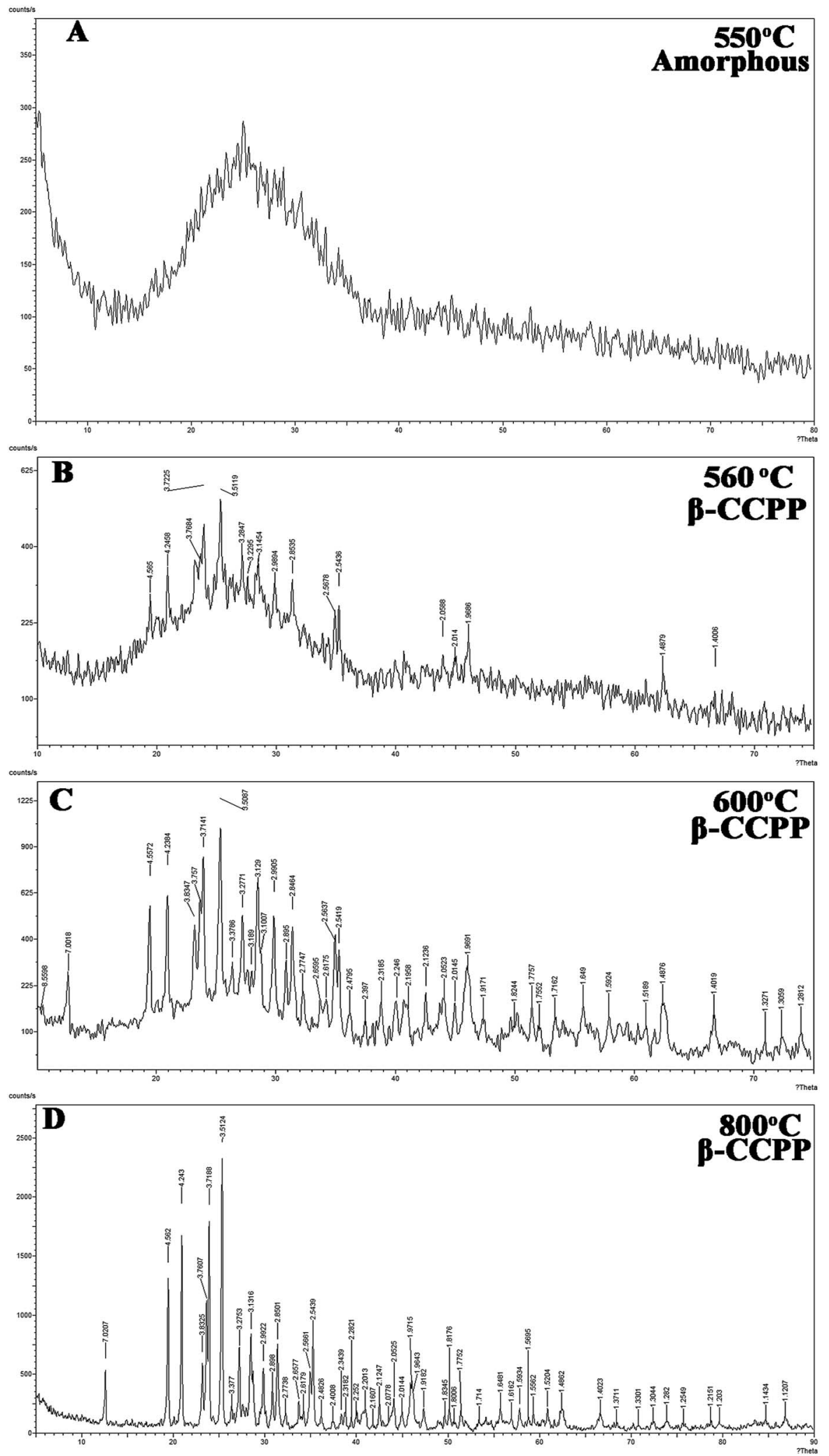

Fig. 1 XRD patterns of CCPP after sintering at different temperature: (A) $550^{\circ} \mathrm{C}$; (B) $560{ }^{\circ} \mathrm{C}$; (C) $600^{\circ}$; (D) $800^{\circ} \mathrm{C}$.

properties. It is also one of very important factors to determine the feasibility to be used as bone repairing materials or bone tissue engineering scaffolds.
3.2.1 Analysis of the weight loss and ion release of CCPP scaffolds during SBF solution-mediated degradation. Fig. 4 shows the weight loss curve of various CCPP in SBF solution. 


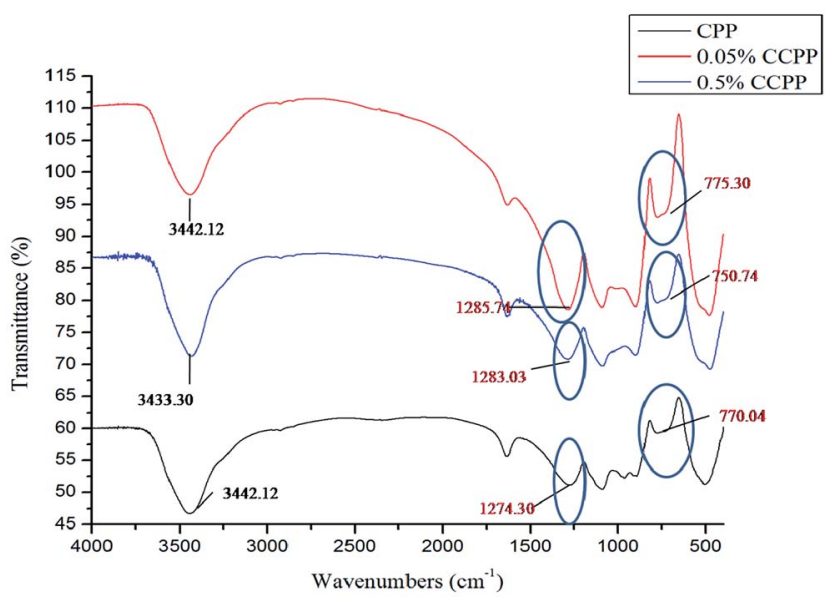

Fig. 2 FTIR spectra of CCPP scaffolds.

The weight loss curves of all scaffolds showed the same trends: a quicker increase at earlier times was followed by a slower increase thereafter and to a nearly constant value at longer times. When the reaction was terminated at 30 days, the final weight loss of scaffolds in SBF solution were $10-16 \%$. In addition, it is obvious that doping copper ions into CPP had impact on degradation behavior of scaffolds when the content of copper was $0.5 \%$. At any time, the weight loss of $0.5 \%$ CCPP was much larger than CPP. However, there were no significant differences in weight loss between CCPP scaffolds doped lowcontent copper ions $(0.01 \%$ and $0.05 \%)$ and CPP scaffold.

Fig. 5 shows cumulative phosphate, $\mathrm{Cu}^{2+}$ and $\mathrm{Ca}^{2+}$ release curve of various CCPP in SBF solution during 30 days. As shown in figure, during experimental session, the ion-release behavior of all scaffolds presented slightly initial burst followed by a slowly sustained release thereafter. At any degradation time, the cumulative amount of $\mathrm{Ca}^{2+}, \mathrm{Cu}^{2+}$ and $\mathrm{PO}_{4}{ }^{3-}$ released into the medium from $0.2 \%$ CCPP and $0.5 \%$ CCPP was more than that from $0.01 \%$ CCPP and $0.05 \%$ CCPP.

As reported, lots of factors, such as the crystal structure, ${ }^{22}$ sintering time and temperature ${ }^{23}$ polymerization degree, ${ }^{24}$ ion doped $^{25}$ and degradation media, ${ }^{26}$ could affect the degradation process of CPP. According to the methods during preparation and degradation experiment in this paper, some factors, such as the crystal structure, sintering time and temperature and polymerization degree of scaffolds must be similar due to the specificity of the preparation process of $\beta$-CCPP. So, we mainly discussed the effects of ion doped and degradation media on the degradation process of scaffolds in this paper. From our results above, we found that doping copper ions into CPP had some effects on degradation behavior of scaffolds. Compared to CPP, the crystal grains of CCPP became tiny and intimately connected with each other, but at the same time, doping copper could induce point defects due to the fact that copper ion radius was bigger than calcium ion radius. ${ }^{27}$ The point defects could result in the changes in degradation behavior of scaffolds. The much the amount of doped copper ions is, the more significant the point defects of scaffolds is. Therefore, CCPP scaffolds doped high-content copper ions $(0.2 \%$ and $0.5 \%)$ had a faster degradation rate than CCPP scaffolds doped low-content copper ions $(0.01 \%$ and $0.05 \%)$ and CPP scaffold. According to it, maybe we could control the degradation rate of CCPP scaffolds through adjusting the amount of copper ions doping into CPP.

3.2.2 Analysis of the weight loss and ion release of CCPP scaffolds during osteoblast-mediated degradation. As shown in Fig. 6, the weight loss of all scaffolds in both group increased continuously with time. Scaffolds in cell group showed a higher degradation rate than those in control group without cell. When the degradation was terminated after 3 weeks, the weight loss of scaffolds in cell group (9.2\%) was larger than that in control

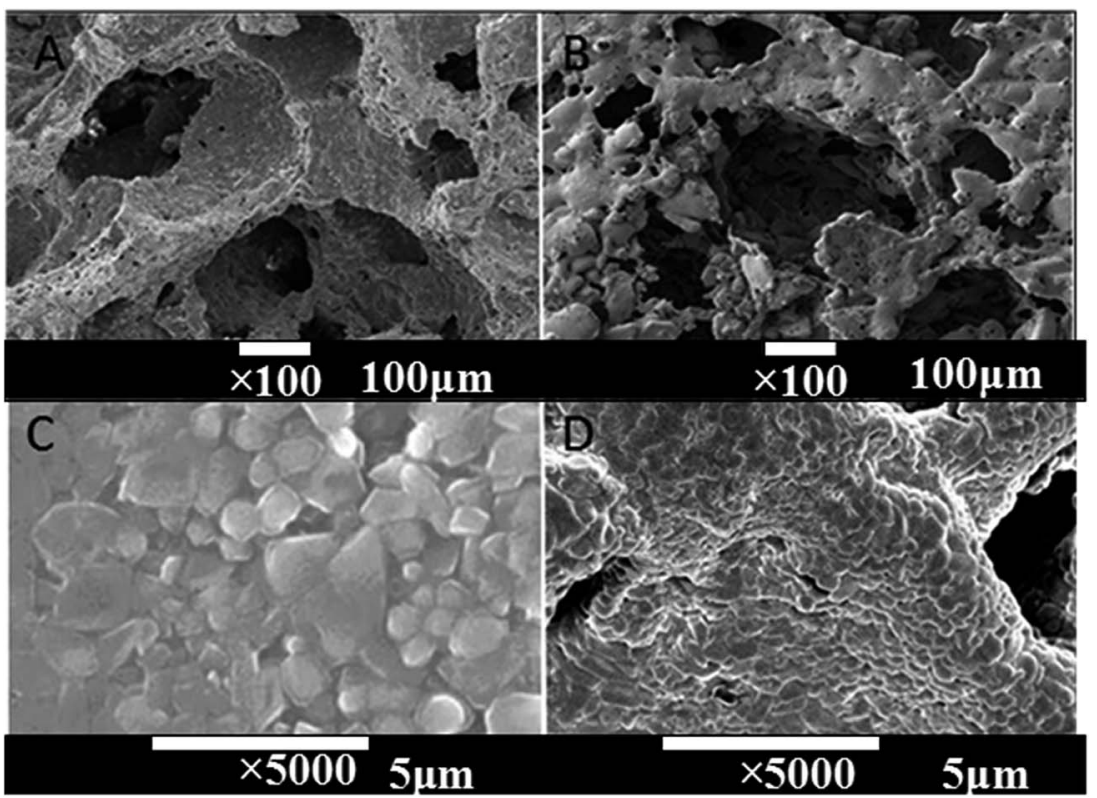

Fig. 3 The SEM images of CPP and CCPP scaffolds ((A) CPP $\times 100$, (B) CCPP $\times 100$, (C) CPP $\times 5000$, (D) CCPP $\times 5000$ ). 
Table 3 The porosity of CCPP scaffolds measured by liquid displacement method

\begin{tabular}{llll}
\hline The amount of pore-forming agent (wt\%) & Theoretical porosity & Measurement porosity & Compressive strength (MPa) \\
\hline 0 & 0 & $28 \%$ & $130-170$ \\
40 & $40 \%$ & $70 \%$ & $5-9$
\end{tabular}

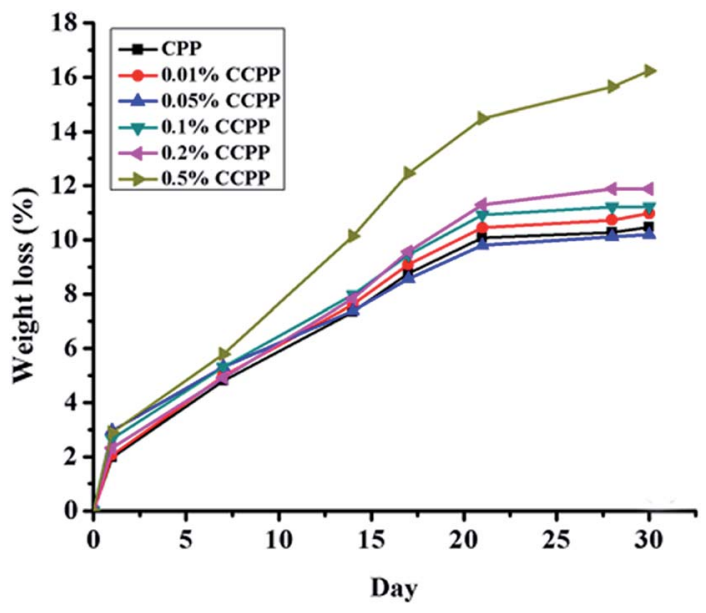

Fig. 4 Weight loss curve of various CCPP in SBF $(n=3)$.

group without cell (6.2-8.0\%). This result could be explained by the reason that the acidic environment created by the acidic metabolites secreted by osteoblasts could accelerate the degradation of scaffolds. Firstly, the porosity of scaffolds could become higher due to the acid condition, which might result in a higher surface area and lead to higher dissolution rate. Secondly, the break of covalent bonds in scaffolds induced by the acid condition could also increase the degradation rate of scaffolds. Finally, the pyrophosphatase, alkaline phosphatase and other acidic enzyme secreted by osteoblasts could also enhance the dissolution of scaffolds in cell group, and thus speed of the degradation of scaffolds in cell group. The degradation of CCPP scaffolds in control group [Fig. 6(b)] presented the same degradation behavior as CCPP scaffolds in solutionmediated degradation. However, all CCPP scaffolds in cell group showed similar degradation rates [Fig. 6(a)]. It might due to that CCPP scaffolds doped low-content copper ions $(0.01 \%$ and $0.05 \%$ ) could promote the proliferation of osteoblasts. Accordingly, there were more osteoblasts to secrete acidic metabolites on CCPP scaffolds doped low-content copper ions in cell group; therefore, the degradation of scaffolds could be enhanced, and CCPP scaffolds doped low-content copper ions in cell group showed a higher degradation rate which was
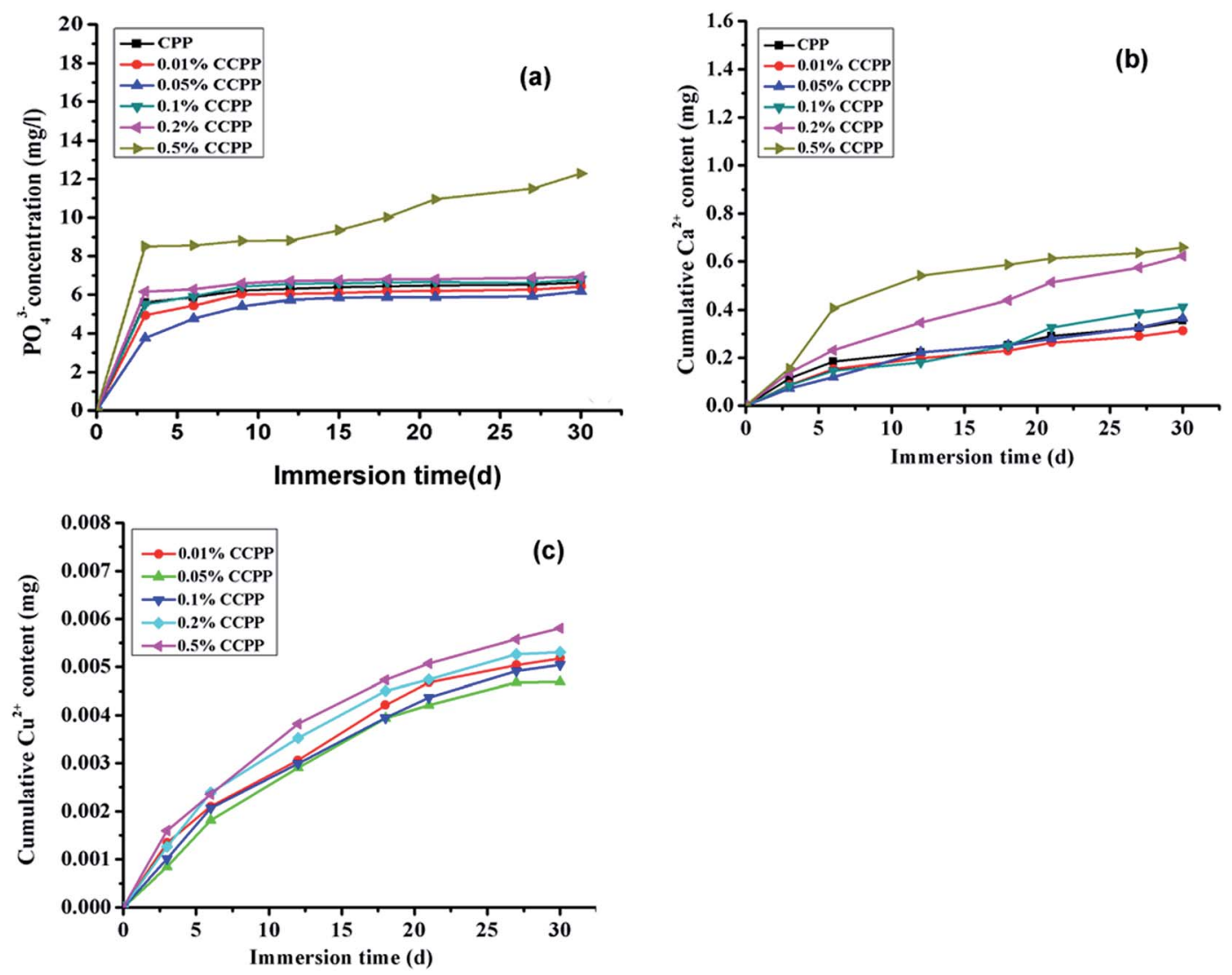

Fig. 5 Cumulative phosphate, $\mathrm{Cu}^{2+}$ and $\mathrm{Ca}^{2+}$ release curve of various $\mathrm{CCPP}$ in $\mathrm{SBF}\left((\mathrm{a}) \mathrm{PO}_{4}{ }^{3-}\right.$, (b) $\left.\mathrm{Ca}^{2+}, \mathrm{SBF} ;(\mathrm{c}) \mathrm{Cu}^{2+}, \mathrm{SBF}, n=3\right)$. 

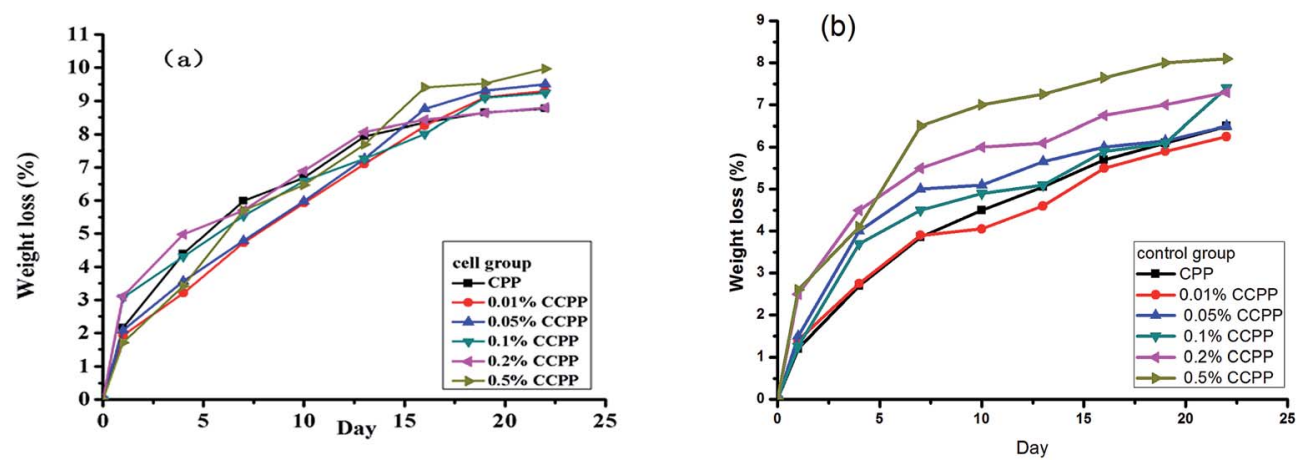

Fig. 6 Weight loss curve of various CCPP in cell and control group without cell during degradation ((a) cell group; (b) control group, $n=3$ ).

similar to CCPP scaffolds doped high-content copper ions $(0.2 \%$ and $0.5 \%$ ).

The concentrations of copper ion exceeding optimal level can result in cytotoxicity. Therefore, the determination of the concentrations of various ions, especially $\mathrm{Cu}^{2+}$, released from CCPP scaffolds cultured with cells is very important. Based on it, the investigation on the cytotoxicity of these CCPP scaffolds must be performed. The cumulative phosphate, $\mathrm{Cu}^{2+}$ and $\mathrm{Ca}^{2+}$ release curve shown in Fig. 7 represented the ion-release behavior of CCPP scaffolds cultured with cell in osteoblastmediated degradation which was similar to CCPP scaffolds in solution-mediated degradation. The cumulative phosphate ion release concentration during osteoblast-mediated degradation ranged from $40 \mathrm{mg} \mathrm{l}^{-1}$ to $70 \mathrm{mg} \mathrm{l}^{-1}\left(0.417-0.729 \mathrm{mmol} \mathrm{l}^{-1}\right)$. According to the investigation performed by Meleti, ${ }^{28}$ inorganic phosphate showed no cytotoxicity at phosphate concentrations of $1 \mathrm{mmol} \mathrm{l}^{-1}$. Moreover, $\mathrm{Wu}^{29}$ also found that $\mathrm{PO}_{4}{ }^{3-}$ entered cells phosphate transporter to stimulate osteopontin (OPN) expression which played an important in the mineralization of osteoblast. Therefore, the cumulative phosphate ion release concentration during degradation in this paper showed no adverse influence on the proliferation of osteoblast and could
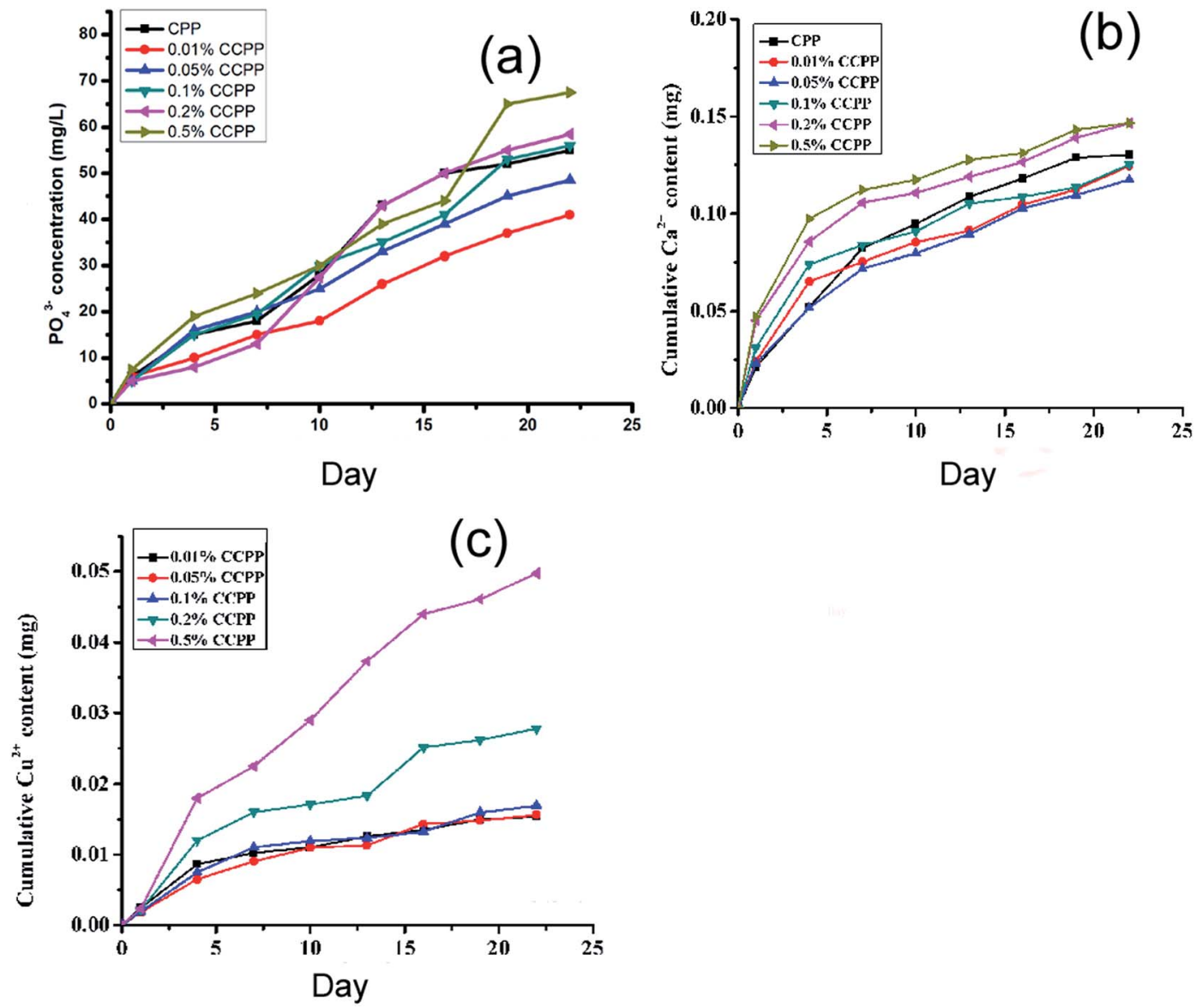

Fig. 7 Cumulative phosphate, $\mathrm{Cu}^{2+}$ and $\mathrm{Ca}^{2+}$ release curve of various $\mathrm{CCPP}$ cultured with cells in cell medium $\left((\mathrm{a}) \mathrm{PO}_{4}{ }^{3-} ;(\mathrm{b}) \mathrm{Ca}^{2+} ;(\mathrm{c}) \mathrm{Cu}^{2+}, n=\right.$ 3). 
induce mineralization of osteoblast. The cumulative calcium ion release concentration during degradation ranged from $0.117 \mathrm{mg}$ to $0.146 \mathrm{mg}(5.85-7.3 \mathrm{mM})$. Maeno S. ${ }^{30}$ suggested that 2-4 $\mathrm{mM} \mathrm{Ca}^{2+}$ was proper for survival and proliferation of osteoblasts, whereas slightly higher concentrations (6-8 mM) were in favor of osteoblast differentiation and matrix mineralization and higher concentrations (>10 mM) were cytotoxic. Also, Nakade $^{31}$ demonstrated that extracellular calcium ion played an important role in calcium hydroxide-induced calcification by modulating OPN and BMP-2 expression in cells. So, during 3 weeks of osteoblast-mediated degradation, the $\mathrm{Ca}^{2+}$ released from CCPP scaffolds could induce the proliferation and mineralization of osteoblasts. The bioactivities of CCPP scaffolds depended largely on copper ions doped into them.

Therefore, compared to $\mathrm{Ca}^{2+}$ and $\mathrm{PO}_{4}{ }^{3-}, \mathrm{Cu}^{2+}$ played a more important role in assessing the cytotoxicity of CCPP scaffolds. Jake found that the normal concentration of $\mathrm{Cu}^{2+}$ was $0.0056-$ $0.056 \mathrm{mg} \mathrm{ml}^{-1} \cdot{ }^{11}$ The cumulative $\mathrm{Cu}^{2+}$ release concentration of CCPP scaffolds doped low-content copper ions $(<0.1 \%)$ during osteoblast-mediated degradation was less than $0.0312 \mathrm{mg} \mathrm{ml}^{-1}$, while the cumulative $\mathrm{Cu}^{2+}$ release concentration of $0.5 \%$ CCPP scaffolds was $0.09948 \mathrm{mg} \mathrm{ml}^{-1}$. It indicated that CCPP scaffolds doped high-content copper ions might show cytotoxicity on osteoblasts. In order to verify this presumption, the cytotoxicity of various CCPP was evaluated by MTT assay. The results were presented in Chapter 3.4 in this paper.
3.2.3 Morphology of CCPP scaffolds before and after 30 d degradation. As shown in Fig. 8(c)-(f), after immersing in the medium for $30 \mathrm{~d}$, many pores were observed on the surface of scaffolds. It indicated that the scaffolds degraded in SBF and culture medium with osteoblast continuously with time. More significant changes of surface morphology were observed on the surfaces of CCPP scaffolds in osteoblast-mediated degradation. After degrading in culture medium with osteoblast for $30 \mathrm{~d}$, the crystal grains of CCPP had been degraded into smaller particles, and the crystal boundaries became blurred. To sum up, according to Fig. 8 and the results of weight loss and ion release above, we found out that CPP and CCPP scaffolds lost the weight and structures of scaffolds changed after during solution-mediated and osteoblast-mediated degradation. Besides, the scaffolds in culture medium with osteoblast showed a higher degradation rate than those in SBF solution.

\subsection{The cytocompatibility of CCPP scaffolds with MG63 human osteoblasts and HUVEC}

The investigation on the cytocompatibility (cytotoxicity) of these CCPP scaffolds was performed in this chapter. Fig. 9 shows the effects of various CCPP scaffold material on osteoblast cells viability. As shown in Fig. 9, all CCPP scaffolds could promote the proliferation of osteoblasts at 2, 4 and 6 days of culture. However, $0.2 \%$ CCPP and $0.5 \%$ CCPP scaffolds inhibited the proliferation of osteoblast while $0.01 \%$ CCPP, $0.05 \%$ CCPP and $0.1 \%$ CCPP scaffolds still enhanced osteoblast proliferation at

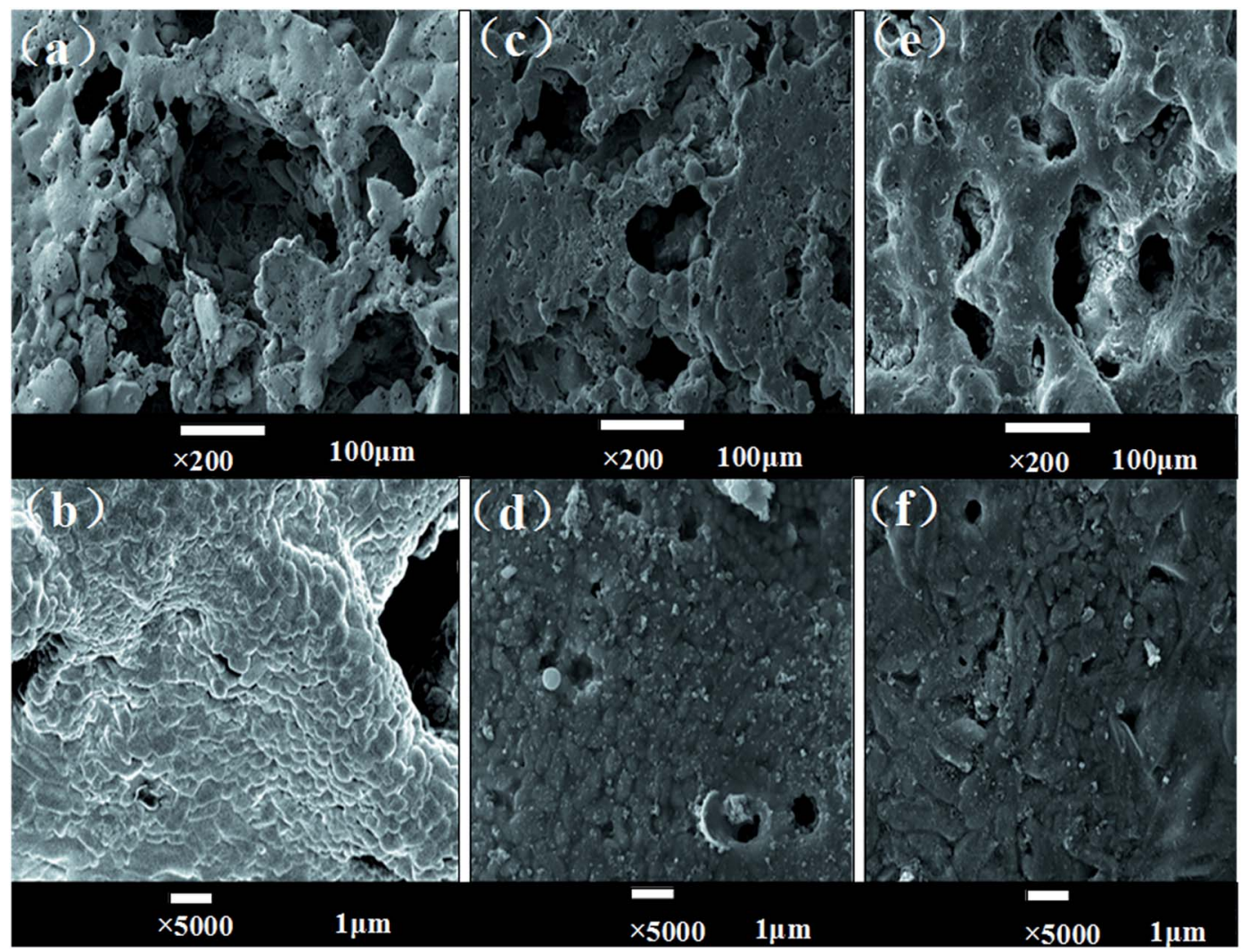

Fig. 8 The SEM images of CCPP scaffold materials before and after 30 d degradation (a) before degradation CCPP $\times 200$, (b) $\times 5000$; (c) degradation in SBF CCPP $\times 200$, (d) $\times 5000$; (e) degradation in culture medium with osteoblast CCPP $\times 200$, (f) $\times 5000$. 


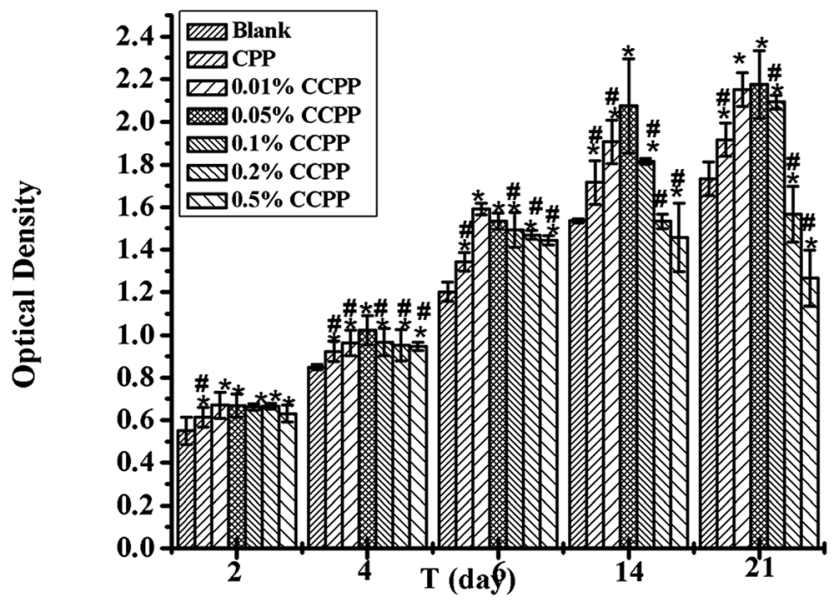

Fig. 9 The effects of various CCPP scaffold materials on osteoblast cells viability (* means the difference attained a statistically significant differences compared to the blank group; \# means the difference attained a statistically significant differences compared to $0.05 \%$ group, $p<0.05, n=3$ ).

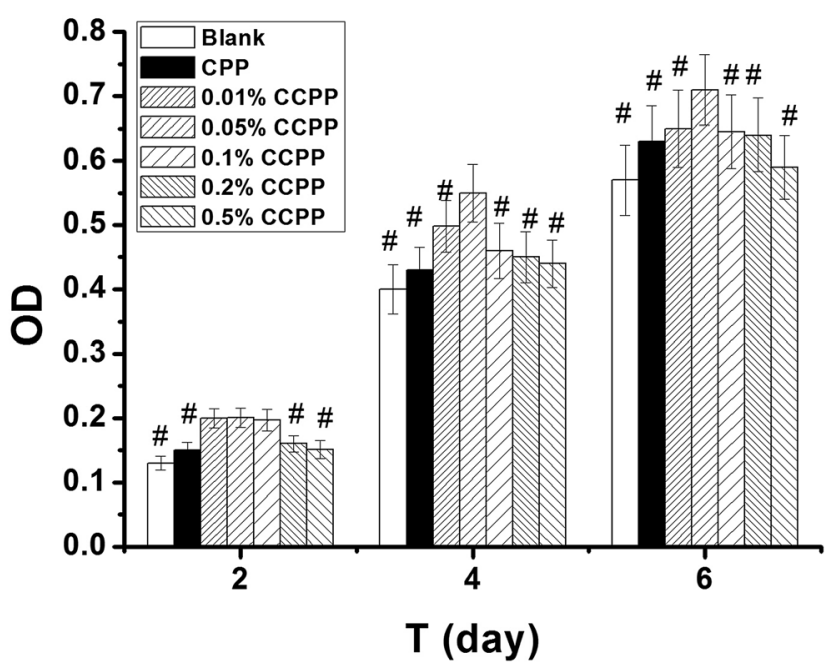

Fig. 10 The effects of various CCPP scaffold materials on HUVECs viability (\# means the difference attained a statistically significant differences compared to $0.05 \%$ group, $p<0.05, n=3$ ).

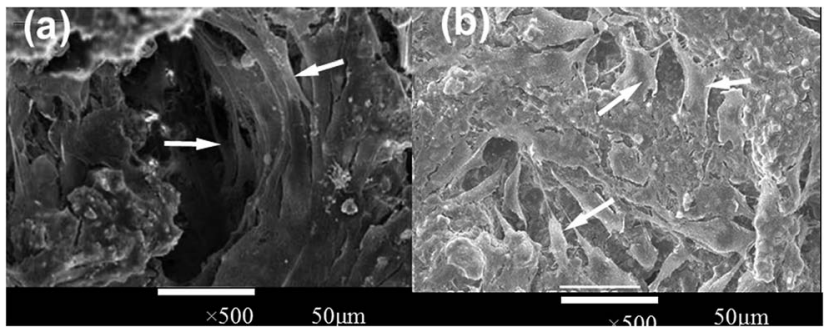

Fig. 12 SEM microscope images of different cells cultured $0.05 \%$ CCPP scaffold ((a) MG63, (b) HUVEC; arrows in (a) refer to MG63, arrows in (b) refer to HUVEC).

14 and 21 days of culture. It suggested that CCPP could accelerate the proliferation of osteoblasts, and it was a $\mathrm{Cu}$ dosedependent manner. CCPP scaffolds doped low-content copper ions showed a good osteoblasts-cytocompatibility. According to the results above, the compressive strength of CCPP scaffolds with the porosity of $70 \%$ was 5-9 MPa which met the strength requirements of cancellous bone (2-12 MPa) and the incorporation of $\mathrm{Cu}^{2+}$ a could promote the degradation of CCPP scaffolds, we inferred that $0.05 \%$ CCPP was the optimal one.

Bone growth greatly relies on the vascular network to transport nutrients/metabolites. ${ }^{32}$ It is well known that the development of blood vessel always precedes the osteogenesis. ${ }^{33}$ Under the circumstance of a well-developed vascular network, the osteoblasts produce osteoid, calcify and differentiate to osteocytes, and present healthy bone growth. Therefore, it is necessary to study on the effects of various CCPP scaffold materials on the viability of human vascular endothelial cells (HUVECs) which play a crucial role in the formation of new vascular network. Fig. 10 showed that all CCPP scaffolds could promote the proliferation of HUVECs at 2 and 4 days of culture. However, $0.5 \%$ CCPP scaffolds began to inhibit the proliferation of HUVEC at 6 days of culture. It indicated the acceleration of CCPP scaffolds for the proliferation of HUVECs with a Cu dosedependent manner similar to osteoblast cells. 0.05\% CCPP was also the optimal one.

The reason for the cytocompatibility-results of these CCPP scaffolds might be due to that the cell-growth

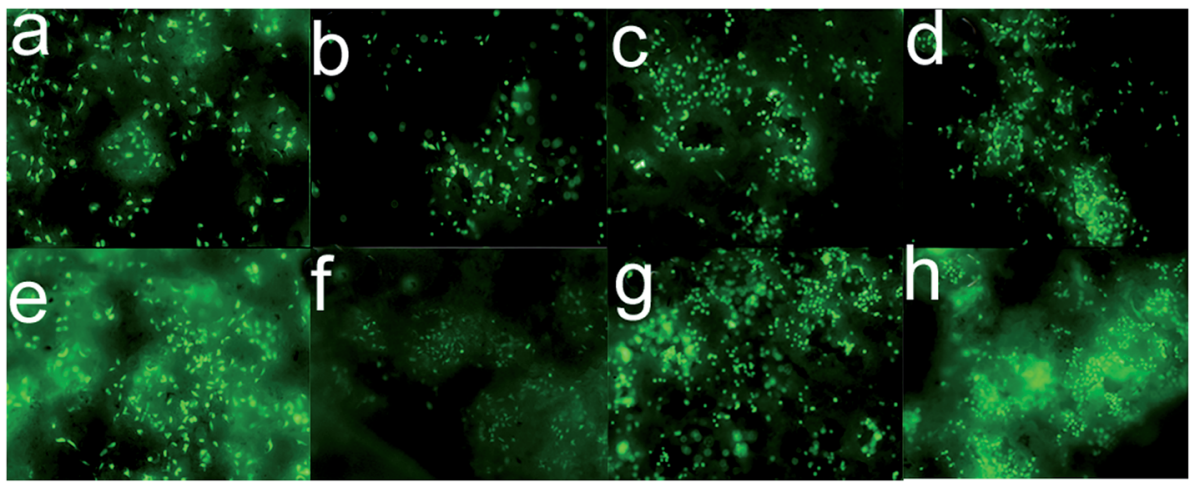

Fig. 11 Fluorescence microscope images of MG63 and HUVECs cultured with CPP and $0.05 \%$ CCPP scaffolds on the $4^{\text {th }}$ day ((a) the surface of CPP, MG63; (b) inside of CPP, MG63; (e) the surface of 0.05\% CCPP, MG63; (f) inside of 0.05\% CCPP, MG63; (c) the surface of CPP, HUVECs; (d) inside of CPP, HUVECs; (g) the surface of $0.05 \%$ CCPP, HUVECs; (h) inside of $0.05 \%$ CCPP, HUVECs). 


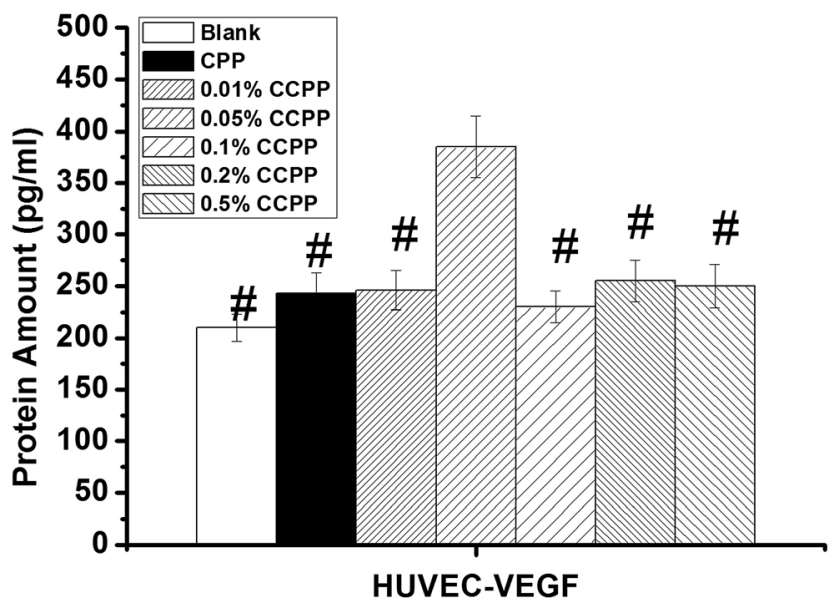

Fig. 13 The effect of various CCPP scaffolds on VEGF secretion from HUVEC cultured with materials (\# means the difference attained a statistically significant differences compared to $0.05 \%$ group, $p<$ $0.05, n=3)$.

microenvironment created by $\mathrm{Ca}^{2+}, \mathrm{PO}_{4}{ }^{3-}$ and $\mathrm{Cu}^{2+}$ released from CCPP scaffolds doped low-content copper ions could enhance the proliferation of HUVECs and osteoblast. Hu found that copper could stimulates the proliferation of endothelial cell at the concentration of $500 \mu \mathrm{M}$ after 48 hours. ${ }^{34}$ Ewald also found that copper could enhances the proliferation of osteoblastic cells on calcium phosphate cements (CPC) at the concentration of $0.56 \mu \mathrm{g} \mathrm{cm}{ }^{-2}$ after 10 days. ${ }^{35}$ On the other hand, a high content of copper ions released from scaffolds might show cytotoxicity on HUVECs and osteoblasts, resulting in that $0.5 \%$ CCPP scaffolds inhibited the proliferation of HUVECs (after 6 days) and osteoblast (after 14 days).

Fig. 9 and 10 both indicated that $0.05 \%$ CCPP scaffolds showed the best proliferation on MG63 and HUVECs. We further investigated the growth of cells (HUVECs and osteoblasts) on/within the $0.05 \%$ CCPP scaffolds by fluorescence microscope [Fig. 11]. Fig. 11 indicated the same results that 0.05\% CCPP scaffolds could promote the proliferation of MG63 and HUVECs compared to CPP scaffolds. Moreover, there were more MG63 and HUVECs observed inside of $0.05 \%$ CCPP compared to CPP scaffolds. This might be due to that copper ions have the ability to induce endothelial cell migration. ${ }^{36} \mathrm{Also}$, Fig. 12 shows the SEM images of MG63 and HUVEC cultured on the $0.05 \%$ CCPP scaffolds after 21 days of culture. The adhered cells developed numerous cellular processes (lamellipodia and filopodia) to facilitate cell-substrate and cell-cell interactions. The lamellipodia structure could be noticed in the figure, which indicated the preferable, strong interactions between cells and CCPP. So we inferred that both MG63 and HUVEC had a good adhesion and growth on the $0.05 \%$ CCPP. Above all, $0.05 \%$ CCPP scaffolds could promote the proliferation and migration of MG63 and HUVECs, which indicate its potential osteogenesis and angiogenesis.

\subsection{The effects of CPP and CCPP scaffolds on osteogenic and angiogenic growth factors secretion from osteoblasts/ endothelial cells}

The results shown in Fig. 13 and 14 indicated that $0.05 \%$ CCPP scaffolds could promote the secretion of all these osteogenic
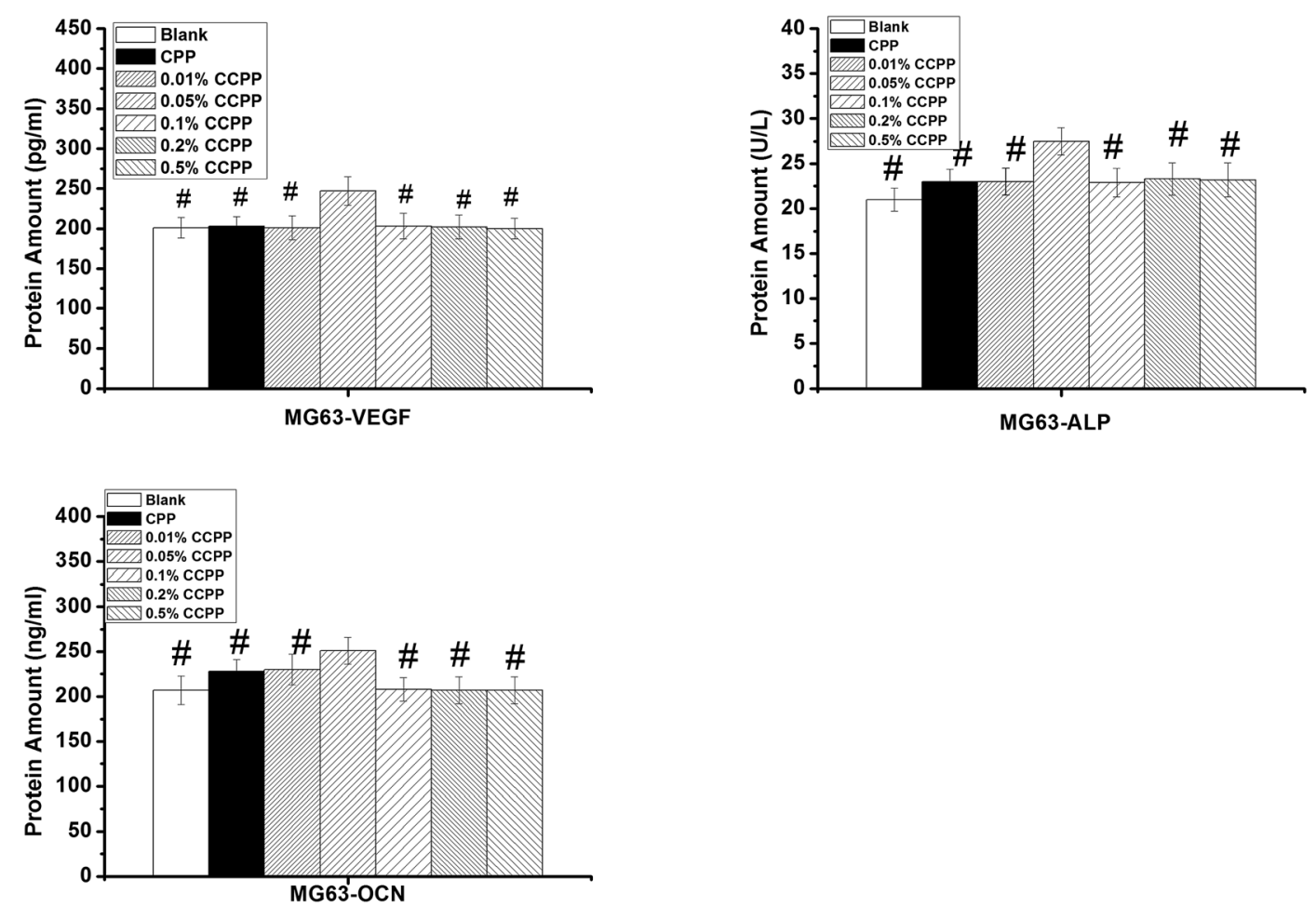

Fig. 14 The effect of various CCPP scaffolds on VEGF, ALP and OCN secretion from MG63 cultured with materials (\# means the difference attained a statistically significant differences compared to $0.05 \%$ group, $p<0.05, n=3$ ). 
and angiogenic growth factors obviously. Proper content copper ions released from $0.05 \%$ CCPP scaffolds might have active effects on the secretion of all these growth factors. However, $0.1 \%, 0.2 \%, 0.5 \%$ CCPP scaffolds released excessive copper ions, which resulted in cytotoxicity, and then inhibited the secretion of these growth factors from cells.

As we all know, doping $\mathrm{Cu}^{2+}$ ions into bioactive scaffolds could mimick hypoxia and stabilize the expression of hypoxiainducible factor $(\mathrm{HIF}-1 \alpha){ }^{\mathbf{1 5}}$ It has been generally acknowledged that HIF-1 $\alpha$ plays an important role in stimulating cells to express VEGF. ${ }^{37}$ HIF- $1 \alpha$ acts as a promoter for VEGF gene, it can induce the expression of VEGF in hypoxia conditions. Therefore, $0.05 \%$ CCPP scaffolds could promote the secretion of VEGF from HUVECs/osteoblasts. VEGF is a very important angiogenic growth factor which activates endothelial cells in the surrounding tissues by regulating their proliferation, migration, and finally promotes the formation of tubular structures. ${ }^{38}$ In addition, the investigation undertaken by $\mathrm{Wu}^{15}$ indicated that the copper ions could promote the expression of bonerelated gene such as OCN, OPN and ALP. This could be the reason for the better promotion of $0.05 \%$ CCPP scaffolds on the secretion of ALP and OCN from MG63. OCN is known as a key marker for osteogenic differentiation and ALP, which is expressed during the post-proliferative period of extracellularmatrix maturation, has been widely recognized as a marker for osteoblast differentiation. So, it is concluded that $0.05 \%$ CCPP scaffolds show a notable ability to stimulate osteogenesis, which plays a crucial role in the formation of new bone. As mentioned in introduction, the energy produced by the breakage of $\mathrm{P} \backslash \mathrm{O} \backslash \mathrm{P}$ bonds between $\left[\mathrm{PO}_{3}{ }^{-}\right]$units in CCPP, which was similar to the breaking of high-energy anhydride linkages in the adenosine triphosphate, could be used for cell-growth, which might also be the reason why $0.05 \%$ CCPP could promote the secretion of all these growth factors. Compared with other Cu-containing biomaterials such as copper-doped hydroxyapatite, $0.05 \%$ CCPP scaffolds showed better cytocompatibility and ability to stimulate osteogenesis and angiogenesis due to the synergy effects of copper and the energy produced by the breakage of $\mathrm{P} \backslash \mathrm{O} \backslash \mathrm{P}$ bonds between $\left[\mathrm{PO}_{3}{ }^{-}\right]$units in CCPP. In summary, the results obtained in this study suggested that $0.05 \%$ CCPP scaffold was a promising biomaterial for bone repairing application.

\section{Conclusion}

In this paper, a novel Cu-containing porous scaffold, namely copper-doped calcium polyphosphate, was successfully prepared, and its biological performances and degradation behavior in vitro were investigated. The results suggested that low-content copper doping showed no significant influence on the structure of CPP scaffolds. The compressive strength of CCPP scaffolds with the porosity of 70\% was 5-9 MPa which met the strength requirements of cancellous bone (2-12 MPa). In degradation experiment, the results suggested that both the incorporation of $\mathrm{Cu}^{2+}$ and acidic metabolites from osteoblasts could promote the degradation of CCPP scaffolds. Also, analysis of the concentration of $\mathrm{Cu}^{2+}, \mathrm{Ca}^{2+}$ and $\mathrm{PO}_{4}{ }^{3-}$ released from various scaffolds in osteoblast-mediated degradation was performed to elucidate the cytocompatibility of CCPP scaffolds with HUVECs/osteoblasts, and then their osteogenic and angiogenic properties were exploited. The results demonstrated that $0.05 \%$ CCPP scaffolds showed the good promotion on the proliferation of MG63 and HUVEC. The results also suggested that $0.05 \%$ CCPP scaffold could promote the secretion of VEGF, ALP and OCN from osteoblasts as well as VEGF from HUVECs, which indicated its good ability to stimulate osteogenesis and angiogenesis. All results obtained in our study suggest that 0.05\% CCPP scaffold is a promising biomaterial for bone repairing application. We believe that our research provides a way to improve the properties of bioceramics and extend the applications of bone tissue engineering. It can give inspiration to others to focus on the applications and development of bioceramics.

\section{Conflicts of interest}

There are no conflicts of interest to declare.

\section{Acknowledgements}

The authors would like to thank the Scientific and Technological Project of Chengdu (No. 2014-HM01-00207-SF) and Sichuan University-Luzhou Strategic Partnership Scientific and Technological Cooperation Projects (No. 2014CDLZ-S27).

\section{References}

1 R. Dimitriou, E. Jones, D. McGonagle, et al., Bone regeneration: current concepts and future directions, $B M C$ Med., 2011, 9(1), 66; L. L. Hench, Bioceramics, a clinical success, Am. Ceram. Soc. Bull., 1998, 77(7), 67-74.

2 L. L. Hench, Bioceramics, a clinical success, Am. Ceram. Soc. Bull., 1998, 77(7), 67-74.

3 T. G. Kim, H. Shin and D. W. Lim, Biomimetic scaffolds for tissue engineering, Adv. Funct. Mater., 2012, 22(12), 24462468.

4 T. D. Fang, A. Salim, W. Xia, et al., Angiogenesis is required for successful bone induction during distraction osteogenesis, J. Bone Miner. Res., 2005, 20(7), 1114-1124.

5 W. G. De Long, T. A. Einhorn, K. Koval, et al., Bone grafts and bone graft substitutes in orthopaedic trauma surgery: a critical analysis, J. Bone Jt. Surg., Am. Vol., 2007, 89(3), 649-658.

6 I. Ahmed, M. Lewis, I. Olsen, et al., Phosphate glasses for tissue engineering: part 1. Processing and characterisation of a ternary-based $\mathrm{P}_{2} \mathrm{O}_{5}-\mathrm{CaO}-\mathrm{Na}_{2} \mathrm{O}$ glass system, Biomaterials, 2004, 25(3), 491-499.

7 R. L. Prabhakar, S. Brocchini and J. C. Knowles, Effect of glass composition on the degradation properties and ion release characteristics of phosphate glasspolycaprolactone composites, Biomaterials, 2005, 26(15), 2209-2218.

8 R. M. Pilliar, M. J. Filiaggi, J. D. Wells, et al., Porous calcium polyphosphate scaffolds for bone substitute applicationsin vitro characterization, Biomaterials, 2001, 22(9), 963-972. 
9 K. Qiu, X. J. Zhao, C. X. Wan, et al., Effect of strontium ions on the growth of ROS17/2.8 cells on porous calcium polyphosphate scaffolds, Biomaterials, 2006, 27(8), 12771286.

10 C. Gérard, L. J. Bordeleau, J. Barralet, et al., The stimulation of angiogenesis and collagen deposition by copper, Biomaterials, 2010, 31(5), 824-831.

11 J. Barralet, U. Gbureck, P. Habibovic, et al., Angiogenesis in calcium phosphate scaffolds by inorganic copper ion release, Tissue Eng., Part A, 2009, 15(7), 1601-1609.

12 A. Hoppe, N. S. Güldal and A. R. Boccaccini, A review of the biological response to ionic dissolution products from bioactive glasses and glass-ceramics, Biomaterials, 2011, 32(11), 2757-2774.

13 L. Finney, S. Vogt, T. Fukai, et al., Copper and angiogenesis: unravelling a relationship key to cancer progression, Clin. Exp. Pharmacol. Physiol., 2009, 36(1), 88-94.

14 N. Philips, H. Hwang, S. Chauhan, et al., Stimulation of cell proliferation and expression of matrixmetalloproteinase-1 and interluekin-8 genes in dermal fibroblasts by copper, Connect. Tissue Res., 2010, 51(3), 224-229.

15 C. Wu, Y. Zhou, M. Xu, et al., Copper-containing mesoporous bioactive glass scaffolds with multifunctional properties of angiogenesis capacity, osteostimulation and antibacterial activity, Biomaterials, 2013, 34(2), 422-433.

16 J. A. Rodriguez, J. S. Valentine, D. K. Eggers, et al., Familial amyotrophic lateral sclerosis-associated mutations decrease the thermal stability of distinctly metallated species of human copper/zinc superoxide dismutase, $J$. Biol. Chem., 2002, 277(18), 15932-15937.

17 L. M. Gaetke and C. K. Chow, Copper toxicity, oxidative stress, and antioxidant nutrients, Toxicology, 2003, 189(1), 147-163.

18 Y. H. Hung, A. I. Bush and R. A. Cherny, Copper in the brain and Alzheimer's disease, JBIC, J. Biol. Inorg. Chem., 2010, 15(1), 61-76.

19 T. Kokubo and H. Takadama, How useful is SBF in predicting in vivo bone bioactivity?, Biomaterials, 2006, 27(15), 2907-2915.

20 R. P. Mihajlovic, V. M. Kaljevic, M. P. Vukasinovic, et al., Spectrophotometric method for the determination of phosphorus in natural waters using the bismuthphosphomolybdate complex, Water SA, 2007, 33(4), 513-517.

21 Q. Wang, Q. Wang and C. Wan, Effect of porosity on the structure and properties of calcium polyphosphate bioceramics, Ceram.-Silik., 2011, 55(1), 43-48.

22 K. Qiu, C. X. Wang, Q. Zhang, et al., In vitro degradation studies of calcium polyphosphate ceramics prepared by controlled degree of polymerization and crystallization, Key Eng. Mater., 2005, 288, 553-556.

23 W. Zhang, Y. Shen, H. Pan, et al., Effects of strontium in modified biomaterials, Acta Biomater., 2011, 7(2), 800-808.
24 Y. L. Ding, Y. W. Chen, Y. J. Qin, et al., Effect of polymerization degree of calcium polyphosphate on its microstructure and in vitro degradation performance, $J$. Mater. Sci.: Mater. Med., 2008, 19(3), 1291-1295.

25 K. Qiu, C. X. Wan, C. S. Zhao, et al., Fabrication and characterization of porous calcium polyphosphate scaffolds, J. Mater. Sci., 2006, 41(8), 2429-2434.

26 Q. Wang, Q. Wang, J. Wang, et al., Degradation kinetics of calcium polyphosphate bioceramic: an experimental and theoretical study, Mater. Res., 2009, 12(4), 495-501.

27 R. Raji and K. G. Gopchandran, ZnO: $\mathrm{Cu}$ nanorods with visible luminescence: copper induced defect levels and its luminescence dynamics, Mater. Res. Express, 2017, 4(2), 025002.

28 Z. Meleti, I. M. Shapiro and C. S. Adams, Inorganic phosphate induces apoptosis of osteoblast-like cells in culture, Bone, 2000, 27(3), 359-366.

29 X. Wu, N. Itoh, T. Taniguchi, et al., Requirement of calcium and phosphate ions in expression of sodium-dependent vitamin $\mathrm{C}$ transporter 2 and osteopontin in MC3T3-E1 osteoblastic cells, Biochim. Biophys. Acta, Mol. Cell Res., 2003, 1641(1), 65-70.

30 S. Maeno, Y. Niki, H. Matsumoto, et al., The effect of calcium ion concentration on osteoblast viability, proliferation and differentiation in monolayer and 3D culture, Biomaterials, 2005, 26(23), 4847-4855.

31 O. Nakade, K. Takahashi, T. Takuma, et al., Effect of extracellular calcium on the gene expression of bone morphogenetic protein-2 and-4 of normal human bone cells, J. Bone Miner. Metab., 2001, 19(1), 13-19.

32 R. K. Jain, Molecular regulation of vessel maturation, Nat. Med., 2003, 9(6), 685-693.

33 R. A. D. Carano and E. H. Filvaroff, Angiogenesis and bone repair, Drug discovery today, 2003, 8(21), 980-989.

$34 \mathrm{G}$. Hu, Copper stimulates proliferation of human endothelial cells under culture, J. Cell. Biochem., 1998, 69(3), 326-335.

35 A. Ewald, C. Käppel, E. Vorndran, et al., The effect of Cu (II)loaded brushite scaffolds on growth and activity of osteoblastic cells, J. Biomed. Mater. Res., Part A, 2012, 100(9), 2392-2400.

36 B. R. McAuslan and G. A. Gole, Cellular and molecular mechanisms in angiogenesis, Trans. Ophthalmol. Soc. U. K., 1980, 100(3), 354-358.

37 P. H. Maxwell, M. S. Wiesener, G. W. Chang, et al., The tumour suppressor protein VHL targets hypoxia-inducible factors for oxygen-dependent proteolysis, Nature, 1999, 399(6733), 271-275.

38 S. Soker, M. Machado and A. Atala, Systems for therapeutic angiogenesis in tissue engineering, World J. Urol., 2000, 18(1), 10-18. 